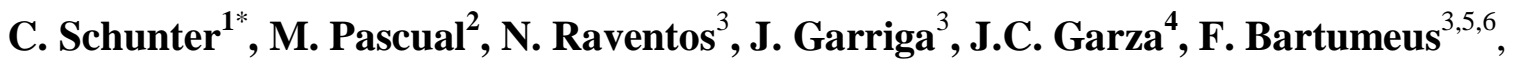

\title{
E. Macpherson $^{3}$
}

${ }^{1}$ Swire Institute of Marine Science \& School of Biological Sciences, University of Hong

${ }^{2}$ Dept. Genètica, Microbiologia i Estadística - IRBio, Universitat Barcelona, Diagonal 643, 08028 Barcelona, Spain

${ }^{3}$ Centre d'Estudis Avançats de Blanes (CEAB-CSIC), Car. Acc. Cala St. Francesc 14, Blanes, 17300 Girona, Spain

${ }^{4}$ Southwest Fisheries Science Center, National Marine Fisheries Service and University of California, 110 McAllister Way, Santa Cruz 95060, USA.

$16{ }^{6}$ ICREA, Passeig de Lluís Companys, 23, 08010 Barcelona.

*Corresponding author: celiaschunter@gmail.com

Keywords: seascape genetics, larval dispersal, genetic patchiness, population connectivity, binary clustering

24 Short Title: Fine-scale genetic population clustering of Tripterygion delaisi 
27 Dispersal is a main determining factor of population structure and variation. In the 28 marine habitat, well-connected populations with large numbers of reproducing 29 individuals are common but even so population structure can exist on a small-scale. 30 Variation in dispersal between populations or over time is often associated to both 31 environmental and genetic variation. Nonetheless, detecting structure and dispersal 32 variation on a fine-scale within marine populations still remains a challenge. Here we 33 propose and use a novel approach of combining a clustering model, early-life history trait 34 information from fish otoliths, spatial coordinates and genetic markers to detect very 35 fine-scale dispersal patterns. We collected 1573 individuals (946 adults and 627 36 juveniles) of the black-faced blenny across a small-scale $(2 \mathrm{~km})$ coastline as well as at a 37 larger-scale area $(<50 \mathrm{kms})$. A total of 178 single nucleotide polymorphism markers were 38 used to evaluate relatedness patterns within this well-connected population. Local 39 retention and/or dispersal varied across the $2 \mathrm{~km}$ coastline with higher frequency of

40 SHORT-range disperser adults; representing local recruitment; towards the southwest of 41 the area. An inverse pattern was found for juveniles, showing an increase of SHORT42 range dispersers towards the northeast. This reveals a complex but not full genetic mixing 43 and suggests oceanic/coastal circulation as the main driver of this fine-scale chaotic 44 genetic patchiness within this otherwise homogeneous population. When focusing on the 45 patterns within one recruitment season, we found large differences in temperatures (from 46 approx. $17^{\circ} \mathrm{C}$ to $25^{\circ} \mathrm{C}$ ) as well as pelagic larval duration (PLD) for juveniles from the 47 beginning of the season and the end of the season. We were able to detect fine-scale 48 differences in HIGH-range juvenile dispersers, representing distant migrants, depending 49 on whether they were born at the beginning of the season, hence, with a longer PLD, or at 50 the end of the reproductive season. The ability to detect such fine-scale dispersal 51 patchiness will aid in our understanding of the underlying mechanisms of population 52 structuring and chaotic patchiness in a wide range of species even with high potential 53 dispersal abilities. 
57 In marine ecosystems, larval dispersal and recruitment are the main processes

58 determining the population structure of species and understanding how they maintain

59 connectivity is crucial for effective management (Jones et al. 2009). Although our

60 understanding of larval dispersal in the marine environment has greatly improved over

61 the last several decades (Cowen and Sponaugle 2009), much is still unknown. Most

62 marine organisms exhibit a larval phase where small larvae can, in theory, travel large

63 distances with ocean currents. Marine populations were thus generally thought to have

64 elevated gene flow and little population structure (Mora and Sale 2002). This paradigm

65 has been largely disproven as many recent studies have revealed that genetic population

66 structure can exist across even small spatial scales and self-recruitment is often larger

67 than previously believed (Carreras-Carbonell et al. 2007, Mokhtar-Jamai et al. 2011). In

68 addition, direct measurements of dispersal using pedigree reconstruction analyses have

69 revealed that self-recruitment and recruitment patterns are often heterogeneous and

70 complex (Planes et al. 2009, Almany et al. 2017).

72 Dispersal patterns depend on pelagic larval duration (PLD) (Selkoe and Toonen 2011), 73 reproductive output (Treml et al. 2012), ocean currents (White et al. 2010) or localized 74 eddies and oceanographic retention patterns (Galarza et al. 2009, Schunter et al. 2011).

75 The duration of the larval period is known to influence larval dispersal distance (Connor 76 et al. 2007) and can have a direct relationship with connectivity (Treml et al. 2012, 77 Pascual et al. 2017). Information on pelagic larval duration (PLD) has been used in 78 numerous studies modelling dispersal capabilities, connectivity and for the establishment 79 of networks of Marine Protected Areas (Mumby et al. 2011, Berumen et al. 2012, Melià 80 et al. 2016, Almany et al. 2017). Several studies have shown an influence of ocean 81 temperature on PLD (Connor et al. 2007), indicating that a change in temperature could 82 have a direct influence on population connectivity (Kleypas et al. 2016). Considering the 83 potential increase of sea temperatures due to global climate change (Marbà et al. 2015), 84 studies analyzing the relationships among temperature, PLD and connectivity are 85 essential in marine ecology. 
87 In the last few years, studies of connectivity have used observations of kin, such as 88 parent-offspring pairs or full siblings, to infer the trajectories and distances of larval 89 movement at small scales, but require large sampling efforts and genotype datasets

90 (Saenz-Agudelo et al. 2011, Harrison et al. 2012, D'Aloia et al. 2013, Schunter et al. 91 2014b, Melià et al. 2016, Almany et al. 2017). Further factors determining patterns of 92 dispersal are availability of habitat, environmental selection, behavior or kinship (Gerlach

93 et al. 2007). The population structure of marine organisms can be influenced by the 94 degree to which larvae from different populations or demes are mixed in the plankton 95 (Ben-Tzvi et al. 2012, D’Aloia and Neubert 2018). Some studies have demonstrated the 96 existence of familial structure with marked genetic distances between recruitment

97 cohorts; thus the lack of larval mixing during the planktonic period can lead to chaotic 98 genetic patchiness (Iacchei et al. 2013, Bentley et al. 2014, Selwyn et al. 2016). Other 99 studies, however, have shown that related individuals do not necessarily disperse 100 cohesively, but limited dispersal was the cause of non-random patches of closely related 101 individuals (D'Aloia et al. 2018). Furthermore, the effects of population structure and 102 kinship on the evolution of social behaviors at sea have largely been ignored (Kamel and 103 Grosberg 2013). Therefore, more research is needed in order to understand how dispersal, 104 settlement and survival patterns of related individuals affect the structure of populations 105 in the marine environment.

107 In this study, we analysed fine-scale structure and dispersal patterns of a rocky shore fish 108 species, the black faced blenny (Tripterygion delaisi), using patterns of kinship inferred 109 from single nucleotide polymorphism (SNP) genotypes. We also used a novel approach 110 of binary data clustering to consider the effect of temperature on dispersal. Specifically, 111 we combine larval traits, such as pelagic larval duration, and evaluate selective dispersal 112 patterns via genetic marker heterogeneity in space. This approach is used to detect fine-

113 scale patterns of dispersal of local and recent-migrant recruits, as well as differences 114 between early and late season individuals in a well-connected population of $T$. delaisi, 115 revealing patterns of relatedness that were not previous detected using traditional 116 methods. 


\section{METHODS}

119 Study system and sample collection

$120 T$. delaisi is a small, common, rocky-shore fish from the Mediterranean Sea and the 121 eastern Atlantic (Carreras-Carbonell et al. 2006). Individuals of this species can live to a 122 maximum of three years and adults display high territorial fidelity (Wirtz 1978, De Jonge 123 and Videler 1989). Furthermore, 1-year old individuals are the most abundant component

124 of the reproductive population. The spawning period starts in April, when water 125 temperatures in the study area are ca. $15^{\circ} \mathrm{C}$ and finishes at the end of July, with 126 temperatures of ca. $23^{\circ} \mathrm{C}$ (Raventós and Macpherson 2001). The planktonic larval 127 duration of this species was estimated to be about 2-3 weeks, depending on the water 128 temperature (Macpherson and Raventós 2006). Therefore, this species is a good study 129 organism to analyse the relationships between temperature and dispersal patchiness.

131 Overall, 946 adult and 627 juvenile $T$. delaisi were collected on SCUBA from the coast 132 of Blanes, Spain in the western Mediterranean Sea (41 $\left.{ }^{\circ} 40^{\prime} 30.7^{\prime \prime N} 2^{\circ} 48^{\prime} 14.4 " \mathrm{E}\right)$. Adults 133 were caught with hand nets, body length was measured, and dorsal fin clips were taken 134 non-lethally underwater, and then preserved in $95 \%$ ethanol. Adults were collected 135 during the length of their breeding season from April 2010 to July 2010. Juveniles were 136 also captured with hand nets on SCUBA between July and September 2010 and 137 subsequently used for genetic and otolith analysis. Sea surface temperature readings were 138 taken $5 \mathrm{~m}$ below the surface twice weekly with a Conductivity, Temperature and Depth 139 probe (CTD) at Las Medes Marine Reserve (approximately 40km north of the focal 140 sampling area in Blanes).

142 Two different spatial scales were studied. A $\sim 2 \mathrm{~km}$ stretch of coastline in the vicinity of 143 Blanes (Figure 1) is the small-scale area in which exhaustive searches were performed for 144 all dominant adult males protecting small nests $(\mathrm{N}=793)$, and randomized searches for 145 non-dominant males and females $(\mathrm{N}=153)$, as well as juveniles $(\mathrm{N}=382)$. The large-scale 146 area encompasses the coast towards the southwest and northeast of the small-scale area, 147 spreading over a total of $42 \mathrm{~km}$, where juveniles $(\mathrm{N}=245)$ were collected (Figure 1). 
148 Juveniles were collected in this large-scale area from La Pilona $(2.7922,41.6701 ; \mathrm{N}=1)$,

149 Palomera (2.8078, 41.6781; N=62), Blanes north (2.8181, 41.686; N=13), Clotilde

150 (2.8214, 41.6887; N=23), Lloret de Mar south (2.8402, 41.6929; N=50), Lloret de Mar

151 north $(2.86125,41.699 ; \mathrm{N}=23)$, Tossa de $\operatorname{Mar}(2.934,41.7146 ; \mathrm{N}=74)$. The exact location

152 of collection of every sample in both areas was geo-referenced.

154 Otolith readings

155 Juvenile otoliths (lapilli) were extracted and mounted on microscope slides using 156 thermoplastic glue (Crystalbond 509). To expose all daily increments, the otoliths were 157 mounted and polished using two different grained sandpapers $(3 \mu \mathrm{m}$ and $1 \mu \mathrm{m}$ 158 Imperial lapping film, 3M) to obtain a thin section exposing the nucleus and the first 159 growth ring. Reading of otolith bands was performed using a high-powered microscope 160 with transmitted light (AxioPlan, Zeiss) connected to a ProgRes C10 camera (Jenoptic) 161 and an image analysis system (Raventós and Macpherson 2005). To verify the first 162 growth increment of the otolith, fertilized $T$. delaisi eggs collected in the field were 163 reared in aquaria. First growth bands were checked at day 1 and day 3 post-hatching in 164 ten individuals. This yielded both the timing of formation of the first band and the daily 165 pattern of band deposition, and confirmed that band deposition took place daily from the 166 day of hatching. Otolith marks in this species were always clear and belonged to Type Ia: 167 an abrupt settlement mark with a sharp decrease in increment width across the settlement 168 mark, completed within one increment (Wilson and McCormick 1999, Raventós and 169 Macpherson 2001). The length of pelagic larval duration (PLD) for each individual was 170 determined by counting the number of daily rings visible between the core and the 171 settlement mark, and the age at sampling was determined by counting the total number of 172 bands from core to margin. We analysed the otoliths along the longest radius from the 173 centre to the edge and recorded otolith width during the pelagic larval period. We also 174 recorded the size-at-hatching (radius from core to first increment) and size-at-settlement 175 along the longest axis of the otolith. To minimize errors, all measurements were repeated 176 three times. Trait differences were statistically evaluated in R (v. 3.3.1; RCoreTeam 177 2016). 
179 A total of 200 randomly selected otoliths from juveniles collected in the small-scale area

180 were read. Total body length of the juveniles correlated very well with the determined

181 age by otolith reading (Pearson's $\mathrm{R}=0.9151, \mathrm{p}<0.001$, Supplementary Material Figure

$182 \mathrm{~S} 1$ ), so the age of all 627 juveniles was estimated from body length with the regression

183 equation. We inferred larval traits such as the hatching date for all juveniles by

184 combining the age and the collection date of each individual. To compare the beginning

185 and the end of the reproductive season, juveniles were assigned o two groups: "early

186 juveniles' if born between April and mid-May $(\mathrm{N}=164$ within Blanes and $\mathrm{N}=224$ for

187 the large-scale area) and 'late juveniles', born between the $15^{\text {th }}$ of June and the end of the

188 recruitment season, which is at the beginning of September $(\mathrm{N}=121$ in Blanes and $\mathrm{N}=$

189229 for the large-scale area). Inferred larval traits (size at hatching, size at settlement and

190 pelagic larval duration) were compared between early juveniles ( $\mathrm{N}=78)$ and late juveniles

$191 \quad(\mathrm{~N}=41)$ with otolith readings by t-tests in $\mathrm{R}$.

Genetic analyses

194 All 1573 individuals were genotyped with 192 SNP markers developed for T. delaisi;

195 details of the SNP development can be found in (Schunter et al. 2014b). Markers that

196 were not in Hardy-Weinberg or linkage equilibrium were discarded and the remaining

197178 SNP loci used in subsequent population genetic and parentage analyses, as described

198 in Schunter et al. (2014b). Heterozygosities for each marker and all markers combined

199 were computed with GenAlEx (v. 6.5; Peakall and Smouse 2012). Pairwise relatedness

200 values (r-values) were obtained by using the Queller and Goodnight equation (Goodnight

201 1989) implemented in the SPAGeDi software (Hardy and Vekemans 2002). To find

202 patterns of high or low relatedness amongst thousands of pairwise relatedness values, we

203 used a relatedness 'ratio' to identify individuals with large numbers of high relatedness

204 values. For each individual, the number of r-values above 0.1 was counted and divided by

205 the total number of comparisons. The top $25 \%$ of individuals with the highest ratios were

206 termed 'locals', whereas the samples with the lowest ratios (bottom 25\%) were referred

207 to as 'recent migrants'. Differences in spatial structure of these groups of individuals

208 were evaluated using their geo-referenced locations of collection and with a

209 Kolmogorov-Smirnov test in R. 


\section{Spatial and Genetic Clustering}

212 To evaluate the spatial distribution of kinship we incorporated spatial structuring of

213 samples into the analysis. Latitudes and longitudes for each individual's sampling

214 location were used to find spatial clusters within the small-scale (Blanes) area as well as

215 in the large-scale sampling area. We found a subset of spatial clusters, with the highest

216 likelihood score, with the R package EMCluster (Chen \& Maitra, 2015) and assigned

217 individual geo-localized samples to the respective spatial clusters.

218 To take into account the spatial signature of relatedness estimates, we averaged

219 individual genetic distances considering their spatial clustering across the study area.

220 Specifically, we computed the genetic distances of each individual with each of its 221 conspecifics in the same spatial cluster and with all other individuals (see Figure 2). As

222 pair-wise relatedness values can be negative when using an unbiased estimator, especially

223 in continuous large populations (Amos et al. 2001) we first converted each single 224 relatedness value into a distance between 0 and 1 with the formula $(d=1-(r-a) /(b-a))$, 225 where $\mathrm{a}$ and $\mathrm{b}$ are the minimum and maximum value of relatedness (i.e., $\mathrm{r}$ ), respectively. 226 Thus, for each individual we computed two distinct values of Mean Genetic Distances 227 (MGD): (i) the mean genetic distance of an individual in a given spatial cluster to all the 228 other members of the same cluster (MGDin), and (ii) the mean genetic distance of that 229 individual to the rest of individuals outside of its spatial cluster (MGDout). Finally, we 230 characterized each individual with these two measures and performed an Expectation231 Maximization binary clustering with the R package EmBC (Garriga et al. 2016). This 232 analysis allowed us to partition all individuals according to four categories (Figure 2): 1. 233 MIXED-range dispersers: individuals with low MGD with respect to individuals in their 234 own spatial cluster (MGDin) and low MGD with respect to individuals in other spatial 235 clusters (MGDout), which are most likely individuals with relatively common genotypes 236 that confer medium relatedness values with many other individuals. 2. SHORT-range 237 dispersers: individuals with low MGDin and high MGDout, which therefore are the 238 individuals that have high relatedness to neighboring individuals. 3. MEDIUM-range 239 dispersers: individuals with high MGDin and low MGDout, which are fish that came 240 from the area but from a different spatial cluster. 4. HIGH-range dispersers: individuals 
bioRxiv preprint doi: https://doi.org/10.1101/530451; this version posted January 26,2019 . The copyright holder for this preprint (which was not certified by peer review) is the author/funder, who has granted bioRxiv a license to display the preprint in perpetuity. It is made available under aCC-BY-NC-ND 4.0 International license.

241 with high MGDin and high MGDout, which means that these individuals have very low 242 relatedness with most of the other samples and could be long-distance dispersers from a 243 different genetic population.

244 


\section{RESULTS}

\section{Genetic and phenotypic diversity}

247 We determined the hatch date of each individual and the number of days the larvae spent 248 in the water column with the subset of 200 randomly selected otoliths. The amount of

249 time a larva spent in the water column depended on when in the reproductive season it 250 was born (Pearson's $r=-0.6057, \mathrm{p}<0.001$; Figure S2). Individuals hatching in April can

251 have a planktonic tenure of up to 10 days longer than those hatching in July. No 252 significant differences were found between 'early juveniles' and 'late juveniles' for size253 at-hatching $(\mathrm{t}=1.73, \mathrm{p}=0.086)$ or size-at-settlement $(\mathrm{t}=-1.009, \mathrm{p}=0.32)$. Average PLD

254 was 19.5 days for early juveniles and 16 days for late juveniles and were significantly 255 different $(\mathrm{t}=9.19, \mathrm{p}=2.596 \mathrm{e}-14)$. The data were found to be normally distributed and no 256 significant differences were found between recent migrant and local juveniles, as 257 categorized based on the relatedness ratio nor for any otolith characteristic (size-at258 hatching $\mathrm{t}=0.57, \mathrm{p}=0.56$; size-at-settlement $\mathrm{t}=0.25, \mathrm{p}=0.80 ;$ PLD $\mathrm{t}=-0.08, \mathrm{p}=0.94$ ).

260 No significant differences in heterozygosity were found between juveniles and adults $(\mathrm{t}=$ $261-0.53, \mathrm{p}=0.59)$ nor between early and late juveniles $(\mathrm{t}=-0.95, \mathrm{p}=0.34)$ for all loci 262 combined (Figure S3). Small differences in heterozygosity between early and late 263 juveniles were found when analyzed locus by locus (Figure S4). Relatedness also did not 264 differ between adults and juveniles $(\mathrm{t}=1.301, \mathrm{p}$-value $=0.194$; Figure S5). Due to a 265 longer PLD at the beginning of the season, individuals could potentially travel further 266 distances and disperse further and we might expect differences in the genetic 267 distance/relatedness of these individuals, given that $T$. delaisi larvae are able to travel $26811.5 \mathrm{~km}$ in 10 days (Schunter et al. 2014b). However, the average relatedness values of 269 early juveniles $(-0.00099 \pm 0.015)$ and late juveniles $(-0.00027 \pm 0.015)$ were not 270 significantly different $(\mathrm{t}=-0.55$, $\mathrm{p}$-value $=0.58)$ nor did the relatedness value distribution 271 differ between adults and juveniles (Figure S6). Of the 157 juvenile individuals 272 categorized as 'locals' due to high relatedness ratios, 29 were early juveniles and 17 late 273 juveniles, whereas of the 157 juvenile individuals considered 'recent migrants', with low 274 relatedness ratios, 19 were early and 17 late juveniles. Interestingly, one of the 
275 individuals considered a 'local' is the sole sample from la Pilona (Figure 1) in the

276 southernmost part of the large-scale sampling area.

278 We did not find differences in spatial distribution patterns between adults and juveniles 279 representing two different years of recruitment (Kolmogorov-Smirnov D $=0.438, \mathrm{p}=$ 280 0.09). Immigration of less-related individuals, possibly from more distant populations, 281 into the small-scale area could potentially result in different spatial patterns for these

282 'recent migrants'. Adult migrants were differently distributed when compared to the rest 283 of adults $(\mathrm{D}=0.72, \mathrm{p}<0.001)$ with some differences evident in the southernmost part of 284 the distribution (Figure S7). However, 'recent-migrant' juveniles were not distributed 285 differently from the rest of the juveniles $(\mathrm{D}=0.25, \mathrm{p}=0.6994)$, nor were spatial 286 differences found between early and late 'recent-migrant' juveniles in the small-scale 287 area $(\mathrm{D}=0.125, \mathrm{p}=0.996$; Figure $\mathrm{S} 8)$.

Fine-scale spatial clustering analysis

290 With hundreds of pairwise relatedness comparisons per individual, it is difficult to detect

291 fine-scale genetic structure, although there could be spatial clusters. To evaluate genetic 292 clustering in space, we first found significant spatial clusters in the small-scale area for 293 both adults and juveniles (Figure 3). We found six spatial clusters for the adults and 294 seven in the juvenile samples. The additional cluster found for juveniles (SplClust6; 295 Figure 3 b) is in an area that could correspond to non-suitable habitat for T. delaisi, as we 296 found no adults and only a few juveniles.

298 The proportion of individuals in each cluster that came from the SHORT-range disperser 299 category varied from southwest to northeast along the coastline (Table S1). For juveniles, 300 the frequency of SHORT-range dispersers increased along the coast from the southwest to 301 the northeast, where they constituted $81 \%$ of all fish sampled, whereas the pattern was 302 reversed for adults; that is, the frequency of SHORT-range dispersers decreased from 303 southwest to northeast (Figure 4). In contrast, HIGH-range dispersers, which could be 304 considered immigrants, were less frequent than SHORT-range dispersers at both life 
305 stages/years of recruitment (adults likely recruited in 2009 and juveniles in 2010) and

306 were relatively homogeneously distributed along the coast (Figure 4).

308 Juveniles born at the beginning of the season (early juveniles) and at the end of the season

309 (late juveniles) have differences in pelagic larval duration (Fig S2), and different patterns

310 were also observed for specific spatial clusters (Table 1). Spatial Cluster 4 (Figure 3) is a

311 rocky reef patch called 'La Roca' that is separated from the coastline by sand and has the

312 furthest distance from shore. In Spatial Cluster 4, at the beginning of the season (with

313 longer PLDs), only HIGH-range disperser juveniles were found (Figure 5). These

314 individuals could be immigrants dispersing from distant populations. Late juveniles, with

315 shorter PLDs, on the other hand, had a higher proportion of SHORT-range dispersers

316 compared to HIGH-range dispersers at La Roca (SplClust4) indicating a more local

317 origin. Most HIGH-range dispersers in late juveniles were found in spatial clusters 2 and

3185 (Figure 5).

\section{Large-scale spatial clustering analysis}

321 Genetic spatial clustering for juveniles across the whole large-scale sampling area, 322 spanning a distance of almost $50 \mathrm{~km}$, identified five distinct clusters, four of them 323 including individuals within the small-scale area (Figure 6). Some of the clusters of the 324 large-scale analysis combined clusters identified in the small-scale area. For instance, 325 SplClust 2 of the large-scale analysis (Figure 6) included all individuals of SplClust 2, 3 326 and 4 in the small-scale analysis (Figure 3).

328 The proportion of HIGH-range dispersers, and thus likely immigrants, was very low for

329 the large-scale dispersal area (Table 1). As the large-scale area is almost 50km of 330 coastline, these individuals would have to come from even more distant locations. All 331 clusters had a higher proportion of SHORT-range dispersers than of MEDIUM or HIGH332 range dispersers, except Spatial Cluster 5, which is the northeastern-most sample area, 333 which had a higher proportion of MEDIUM-range dispersers (Table 1), meaning that 334 individuals in this cluster had less genetic relatedness to each other and were more related 335 to the other locations from the southwest. 
bioRxiv preprint doi: https://doi.org/10.1101/530451; this version posted January 26,2019 . The copyright holder for this preprint (which was not certified by peer review) is the author/funder, who has granted bioRxiv a license to display the preprint in perpetuity. It is made available under aCC-BY-NC-ND 4.0 International license.

337 Table 1: Proportion of individuals that belong to each spatial cluster in the large-scale 338 sampling area. The clusters correspond to Figure 6.

\begin{tabular}{|l|r|r|r|r|r|}
\hline $\begin{array}{l}\text { Juveniles large } \\
\text { Scale area }\end{array}$ & SplClust1 & SplClust 2 & SplClust 3 & SplClust 4 & SplClust 5 \\
\hline $\mathrm{N}$ & 98 & 119 & 174 & 79 & 157 \\
\hline $\begin{array}{l}\text { MIXED-range } \\
\text { dispersers }\end{array}$ & 0 & $\mathbf{0 . 6 2}$ & 0.3 & 0.07 & 0.03 \\
\hline $\begin{array}{l}\text { SHORT-range } \\
\text { dispersers }\end{array}$ & $\mathbf{0 . 7}$ & 0.34 & $\mathbf{0 . 5 5}$ & $\mathbf{0 . 7 5}$ & 0.1 \\
\hline $\begin{array}{l}\text { MEDIUM-range } \\
\text { dispersers }\end{array}$ & 0.3 & 0.04 & 0.16 & 0.08 & $\mathbf{0 . 8 4}$ \\
\hline $\begin{array}{l}\text { HIGH-range } \\
\text { dispersers }\end{array}$ & 0 & 0 & 0 & 0.1 & 0.03 \\
\hline
\end{tabular}

339 MIXED-range dispersers: individuals with low Mean Genetic Distance (MGD) with 340 respect to individuals in their own spatial cluster (MGDin) and low MGD with respect to 341 individuals in other spatial clusters (MGDout). SHORT-range dispersers: individuals 342 with low MGDin and high MGDout. MEDIUM-range dispersers: individuals with high 343 MGDin and low MGDout. HIGH-range dispersers: individuals with high MGDin and 344 high MGDout. Values above 0.5 are in bold. 
349 In the present work, we document very fine-scale patterns of dispersal and recruitment in 350 a population of the black-faced blenny (Tripterygion delaisi) on the northern 351 Mediterranean coast of Spain, through the combined use of genetic relatedness indices 352 and a novel approach of binary data clustering that incorporates spatial patterns. In such a 353 well-connected population with large numbers of dispersing individuals, genetic 354 homogeneity would be expected and no population structure or population-wide pairwise 355 relatedness was found with traditional methods (Schunter et al. 2014b). However, binary

356 clustering of genetic relatedness indices mapped into space revealed a slight clustering of 357 T. delaisi individuals with different dispersal patterns. More adult blennies (sampled in 3582010 and recruited mostly in 2009) considered short distance dispersers, were found in 359 the southwestern parts of the small-scale study area. In contrast, juvenile individuals that 360 recruited and were sampled in the following year (2010), had more short distance 361 dispersers in the northeastern part of the $2 \mathrm{~km}$ coastline. Previous population genetic 362 studies of this species with microsatellite loci, in the same small-scale area and the 363 surrounding areas (up to $50 \mathrm{~km}$ ), identified only one genetic unit with high within364 population self-recruitment (Carreras-Carbonell et al. 2006, 2007). Sibship analysis of $T$. 365 delaisi from the same location found that full siblings can recruit many $\mathrm{km}$ apart from 366 each other, further indicating a genetically homogenous population (Schunter et al. 367 2014b). Nonetheless, the binary clustering analysis across the large-scale area 368 demonstrated that a large proportion of juveniles collected northeast of the small-scale 369 sampling region were MEDIUM-range dispersers and thus more related to the juveniles 370 of this sampling region. This could potentially be the result of a previously unknown 371 directional movement of larvae from southwest to northeast. The detection of fine-scale 372 clusters at both small and large-scale study areas potentially associated with oceanic 373 current patterns shows that there is a complex but not full genetic mixing and suggests 374 oceanic/coastal circulation as the main driver of the fine-scale chaotic genetic patchiness 375 within this otherwise homogeneous population. 
378 Chaotic genetic patchiness, a term coined decades ago (Johnson and Black 1982), has

379 become commonly used to describe patterns of genetic diversity and population structure

380 (Selkoe et al. 2006, Iacchei et al. 2013, Bentley et al. 2014). Broquet et al. (2013)

381 conclude through simulations that chaotic genetic patchiness could occur by a

382 combination of genetic drift due to small effective size and collective dispersal at the

383 larval stage. Such collective dispersal would most likely occur through retention of local

384 larvae near the natal site and close to shore, as suggested by hydrodynamic modelling of

385 larval dispersal (James et al. 2002). Even though chaotic genetic patchiness is generally

386 associated with marked genetic distances between cohorts our results seem to be

387 consistent with the dispersal hypothesis as the main driver of our fine-scale genetic

388 patchiness. In essence, the higher degree of relatedness in the southwestern portion of the

389 study area could be a result of a physical retention process of 'locals' at settlement or a

390 collective movement after settlement. Importantly, these aggregations in space vary

391 across two recruitment seasons, an additional sign of dispersal-driven fine-scale chaotic

392 genetic patchiness.

394 The reproductive biology of Tripterygion delaisi could suggest that other mechanisms 395 may play a minor role in generating fine-scale patterns of chaotic genetic patchiness. For

396 this species, the number of adults (i.e., potentially reproductively active) is very large, 397 with more than 1000 individuals on a narrow $2 \mathrm{~km}$ stretch of coastline (Schunter et al. 398 2014b). Reproductively active individuals include females and two types of males, the 399 dominant nest-making male and the sneaker male (De Jonge and Videler 1989). So-called 400 sweepstake reproduction has been shown to cause genetic patchiness in other species 401 (Iacchei et al. 2013, Pusack et al. 2014) and for T.delaisi it could be that a few successful 402 (i.e. the dominant) males contribute to the majority of offspring. However, the testes of $T$. 403 delaisi sneaker males are significantly larger than those of dominant males and gene 404 expression analysis found genes involved in differentiation and development, suggesting 405 that these males are reproductively active (Schunter et al. 2014c). Moreover, in our 406 analyses, we did not find any evidence of sweepstakes reproductive success, as genetic 407 diversity did not decrease between adults and juveniles within the breeding season. 
408 Furthermore, relatedness did not differ for juveniles recruiting at the beginning or at the

409 end of the breeding season. Sweepstakes-driven patchiness thus seems unlikely, but

410 cannot be ruled out, as high variability in the number of contributing adults over time has

411 been shown in other marine fishes (Pusack et al. 2014, Waples 2016).

413 Patchiness could also be due to recruitment differences related to the conditions 414 encountered by larvae. Pelagic larval duration (PLD) varied significantly with the 415 hatching date of the larvae, with PLD up to 10 days shorter at the end of the season than 416 at the beginning. Larvae that spend more time in the water column have more 417 opportunities to disperse further and might include more immigrants from other 418 populations. Yet, a similar proportion of $T$. delaisi migrants arrived early in comparison to 419 late in the season in the whole sampling area. Nonetheless, at 'La Roca' (Spatial Cluster 420 4), a submerged rocky habitat not continuous with the rocky shoreline habitat, all early 421 juveniles collected $(\mathrm{N}=29)$ were $\mathrm{HIGH}-$ range dispersers and can be considered migrants. 422 This could hint at collective dispersal, at least at the beginning of the season, which 423 Broquet and coauthors (2013) suggested as the second source for chaotic genetic 424 patchiness and greater than expected levels of kinship as indicator have been found in 425 other marine organisms (see Eldon et al. 2016). However, a previous study only found 426 one full sibling pair of T. delaisi settling together in the same area (Schunter et al. 2014b) 427 and the fine-scale patchiness pattern might be due largely to seasonal variation in current 428 patterns.

430 Increased ocean temperatures, due to global climate change, have been suggested to 431 decrease connectivity between populations and increase self-recruitment due to a general 432 decline in pelagic larval duration (PLD) at higher temperature (Green and Fisher 2004, 433 Connor et al. 2007, Munday et al. 2009, Kendall et al. 2016). The effect of temperature on 434 larval connectivity has also been modelled and results suggested a considerable change in 435 larval recruitment and connectivity (Lacroix et al. 2017). Such changes in dispersal 436 potential and connectivity in $T$. delaisi could have detrimental effects on population 437 genetic diversity. In our study area, the difference in sea surface temperature between the 438 beginning (April) and the end of the reproductive period (July) is approximately $8^{\circ} \mathrm{C}$. 
439 This is larger than the predicted temperature increase in the western Mediterranean Sea

440 (ca. $0.25^{\circ} \mathrm{C}$ per decade) towards the end of the present century due to climate change (e.g.

441 Marbà et al. 2015). Mean PLD of the black-faced blenny clearly decreases with increased

442 temperature, but in the small-scale area studied here, this has little effect on the overall

443 connectivity of the population since the proportion of individuals arriving from distant

444 localities is similar regardless of PLD or water temperature. Even with a possible

445 reduction in PLD over time due to climate change, intra-annual variation in conditions

446 encountered by larval $T$. delaisi may provide a buffer and allow maintenance of generally

447 well-connected populations.

Conclusion

450 The species Tripterygion delaisi on the Mediterranean coast of Spain is a well-connected

451 unit but appears to have fine-scale structure in both space and time. The combination of

452 geo-localized individual locations, hatching date information, and genotypic SNP data

453 allowed detection of patches of larvae with particular dispersal histories. Yet, very fine-

454 scale genetic patchiness across space and time was only apparent when using binary 455 clustering techniques, previously used primarily for animal movement trajectory 456 segmentation (Garriga et al. 2016). The ability to detect such fine-scale dispersal 457 patchiness will aid in our understanding of the underlying mechanisms of population 458 structuring and chaotic patchiness in a wide range of species, including those with high 459 potential dispersal abilities. 
Collection and field procedures followed the Spanish Laws (Royal Executive Order,

464 53/2013) for Animal Experimentation, in accordance with the European Union 465 directive $(2010 / 63 / \mathrm{UE})$.

SNP assay sequences are deposited at the NCBI dbSNP with accession numbers

468778235193 to 778235848 . Genotypes of Tripterygion delaisi adults and recruits of the

469178 SNP markers can be found in the Supplementary Materials Table S2. R scripts of the $\mathrm{EMbC}$ analyses can be found as Supplementary Data 1.

We are grateful to the Southwest Fisheries Science Center Molecular Ecology and Genetic Analysis Team for support in the lab and helpful comments and Jinliang Wang for his help in converting relatedness into a distance measurement. This work was partially funded by the Spanish Ministry of Science and Innovation through the CTM2017-88080 (AEI/FEDER, UE) project. The authors CS, MP and EM are part of the research groups 2017SGR-1120 and 2017SGR-378 of the Generalitat de Catalunya and 479 
Almany, G. R., S. Planes, S. R. Thorrold, M. L. Berumen, M. Bode, P. Saenz-Agudelo, M. C. Bonin, A. J. Frisch, H. B. Harrison, V. Messmer, G. B. Nanninga, M. A. Priest, M. Srinivasan, T. Sinclair-Taylor, D. H. Williamson, and G. P. Jones. 2017. Larval fish dispersal in a coral-reef seascape. Nature Ecology \& Evolution 1:0148.

Amos, W., J. W. Wilmer, K. Fullard, T. M. Burg, J. P. Croxall, D. Bloch, and T. Coulson. 2001. The influence of parental relatedness on reproductive success. Proceedings of the Royal Society B: Biological Sciences 268:2021-7.

Broquet, T., F. Viard, and J. M. Yearsley. 2013. Genetic drift and collective dispersal can

Ben-Tzvi, O., A. Abelson, S. D. Gaines, G. Bernardi, R. Beldade, M. S. Sheehy, G. L. Paradis, and M. Kiflawi. 2012. Evidence for Cohesive Dispersal in the Sea. PLoS ONE 7:e42672.

Bentley, B., E. Harvey, S. Newman, D. Welch, A. Smith, and W. Kennington. 2014. Local genetic patchiness but no regional differences between Indo-West Pacific populations of the dogtooth tuna Gymnosarda unicolor. Marine Ecology Progress Series 506:267-277.

Berumen, M. L., G. R. Almany, S. Planes, G. P. Jones, P. Saenz-Agudelo, and S. R. Thorrold. 2012. Persistence of self-recruitment and patterns of larval connectivity in a marine protected area network. Ecology and Evolution 2:444-52. result in chaotic genetic patchiness. Evolution 67:1660-75.

Carreras-Carbonell, J., E. Macpherson, and M. Pascual. 2006. Population structure within and between subspecies of the Mediterranean triplefin fish Tripterygion delaisi revealed by highly polymorphic microsatellite loci. Molecular Ecology 15:3527-39.

Carreras-Carbonell, J., E. Macpherson, and M. Pascual. 2007. High self-recruitment levels in a Mediterranean littoral fish population revealed by microsatellite markers. Marine Biology 151:719-727.

Chen, W.-C., and R. Maitra. 2015. EMCluster: EM Algorithm for Model-Based Clustering of Finite Mixture Gaussian Distribution. R Package, URL http://cran.rproject.org/package $=$ EMCluster.

Connor, M. I. O., J. F. Bruno, S. D. Gaines, B. S. Halpern, S. E. Lester, B. P. Kinlan, and J. M. Weiss. 2007. Temperature control of larval dispersal and the implications for marine ecology, evolution, and conservation. Proceedings of the National Academy of Sciences of the United States of America 104:1266-1271.

Cowen, R. K., and S. Sponaugle. 2009. Larval dispersal and marine population connectivity. Annual Review of Marine Science 1:443-466.

D’Aloia, C. C., S. M. Bogdanowicz, J. E. Majoris, R. G. Harrison, and P. M. Buston. 2013. Self-recruitment in a Caribbean reef fish: a method for approximating dispersal kernels accounting for seascape. Molecular Ecology 22:2563-72. 
D'Aloia, C. C., and M. G. Neubert. 2018. The formation of marine kin structure: effects of dispersal, larval cohesion, and variable reproductive success. Ecology 99:23742384.

D’Aloia, C., A. Xuereb, M. Fortin, S. Bogdanowicz, and P. Buston. 2018. Limited dispersal explains the spatial distribution of siblings in a reef fish population. Marine Ecology Progress Series 607:143-154.

Eldon, B., F. Riquet, J. Yearsley, D. Jollivet, and T. Broquet. 2016. Current hypotheses to

Galarza, J. A., J. Carreras-Carbonell, E. Macpherson, M. Pascual, S. Roques, G. F. Turner, and C. Rico. 2009. The influence of oceanographic fronts and early-lifehistory traits on connectivity among littoral fish species. Proceedings of the National Academy of Sciences of the United States of America 106:1473-8.

Garriga, J., J. R. B. Palmer, A. Oltra, and F. Bartumeus. 2016. Expectation-maximization binary clustering for behavioural annotation. PLoS ONE 11:e0151984.

Gerlach, G., J. Atema, M. J. Kingsford, K. P. Black, and V. Miller-Sims. 2007. Smelling home can prevent dispersal of reef fish larvae. Proceedings of the National Academy of Sciences 104:858-863.

Goodnight, D. C. Q. and K. F. 1989. Estimating relatedness using genetic markers. Evolution 43:258-275.

Green, B. S., and R. Fisher. 2004. Temperature influences swimming speed, growth and larval duration in coral reef fish larvae. Journal of Experimental Marine Biology and Ecology 299:115-132.

Hardy, O. J., and X. Vekemans. 2002. Spagedi: a versatile computer program to analyse spatial genetic structure at the individual or population levels. Molecular Ecology Notes 2:618-620.

Harrison, H. B., D. H. Williamson, R. D. Evans, G. R. Almany, S. R. Thorrold, G. R. Russ, K. A. Feldheim, L. van Herwerden, S. Planes, M. Srinivasan, M. L. Berumen, and G. P. Jones. 2012. Larval export from marine reserves and the recruitment benefit for fish and fisheries. Current Biology 22:1023-8.

Iacchei, M., T. Ben-Horin, K. A. Selkoe, C. E. Bird, F. J. García-Rodríguez, and R. J. Toonen. 2013. Combined analyses of kinship and FST suggest potential drivers of chaotic genetic patchiness in high gene-flow populations. Molecular Ecology 22:3476-94.

James, M. K., P. R. Armsworth, L. B. Mason, and L. Bode. 2002. The structure of reef fish metapopulations: modelling larval dispersal and retention patterns. Proceedings of the Royal Society B: Biological Sciences 269:2079-86.

Johnson, M. S., and R. Black. 1982. Chaotic genetic patchiness in an intertidal limpet, Siphonaria sp. Marine Biology 70:157-164. 
Jones, G. P., G. R. Almany, G. R. Russ, P. F. Sale, R. S. Steneck, M. J. H. Oppen, and B. L. Willis. 2009. Larval retention and connectivity among populations of corals and reef fishes: history, advances and challenges. Coral Reefs 28:307-325.

559 De Jonge, J., and J. J. Videler. 1989. Differences between the reproductive biologies of Tripterygion tripteronotus and T. delaisi (Pisces, Perciformes, Tripterygiidae): the adaptive significance of an alternative mating strategy and a red instead of a yellow nuptial colour. Marine Biology 100:431-437.

Kamel, S. J., and R. K. Grosberg. 2013. Kinship and the evolution of social behaviours in the sea. Biology letters 9:20130454.

Kendall, M. S., M. Poti, and K. B. Karnauskas. 2016. Climate change and larval transport in the ocean: fractional effects from physical and physiological factors. Global Change Biology 22:1532-47.

Kleypas, J. A., D. M. Thompson, F. S. Castruccio, E. N. Curchitser, M. Pinsky, and J. R. Watson. 2016. Larval connectivity across temperature gradients and its potential effect on heat tolerance in coral populations. Global Change Biology 22:3539-3549.

Lacroix, G., L. Barbut, and F. A. M. Volckaert. 2017. Complex effect of projected sea temperature and wind change on flatfish dispersal. Global Change Biology 24:85100.

Macpherson, E., and N. Raventós. 2006. Relationship between pelagic larval duration and geographic distribution in Mediterranean littoral fishes. Marine Ecology Progress Series 327:257-265.

Marbà, N., G. Jordà, S. Agustí, C. Girard, and C. M. Duarte. 2015. Footprints of climate change on Mediterranean Sea biota. Frontiers in Marine Science 2. 10.3389.

Melià, P., M. Schiavina, M. Rossetto, M. Gatto, S. Fraschetti, and R. Casagrandi. 2016. Looking for hotspots of marine metacommunity connectivity: a methodological framework. Scientific Reports 6:23705.

Mokhtar-Jamai, K., M. Pascual, J.-B. Ledoux, R. Coma, J.-P. Feral, J. Garrabou, and D. Aurelle. 2011. From global to local genetic structuring in the red gorgonian Paramuricea clavata: the interplay between oceanographic conditions and limited larval dispersal. Molecular Ecology 20:3291-3305.

Mora, C., and P. F. Sale. 2002. Are populations of coral reef fish open or closed? Trends in Ecology \& Evolution 17:422-428.

Mumby, P. J., I. A. Elliott, C. M. Eakin, W. Skirving, C. B. Paris, H. J. Edwards, S. Enríquez, R. Iglesias-Prieto, L. M. Cherubin, and J. R. Stevens. 2011. Reserve design for uncertain responses of coral reefs to climate change. Ecology Letters $14: 132-140$.

593

Munday, P. L., J. M. Leis, J. M. Lough, C. B. Paris, M. J. Kingsford, M. L. Berumen, and J. Lambrechts. 2009. Climate change and coral reef connectivity. Coral Reefs 
Pascual, M., B. Rives, C. Schunter, and E. Macpherson. 2017. Impact of life history traits on gene flow: A multispecies systematic review across oceanographic barriers in the Mediterranean Sea. PLoS ONE 12:e0176419.

Peakall, R., and P. E. Smouse. 2012. GenAlEx 6.5: genetic analysis in Excel. Population genetic software for teaching and research--an update. Bioinformatics (Oxford, England) 28:2537-9.

Planes, S., G. P. Jones, and S. R. Thorrold. 2009. Larval dispersal connects fish populations in a network of marine protected areas. Proceedings of the National Academy of Sciences of the United States of America 106:5693-7.

Pusack, T. J., M. R. Christie, D. W. Johnson, C. D. Stallings, and M. A. Hixon. 2014. Spatial and temporal patterns of larval dispersal in a coral-reef fish metapopulation: evidence of variable reproductive success. Molecular Ecology 23:3396-3408.

Raventós, N., and E. Macpherson. 2001. Planktonic larval duration and settlement marks on the otoliths of Mediterranean littoral fishes. Marine Biology 138:1115-1120.

Raventós, N., and E. Macpherson. 2005. Environmental influences on temporal patterns of settlement in two littoral labrid fishes in the Mediterranean Sea. Estuarine, Coastal and Shelf Science 63:479-487.

RCoreTeam. 2016. R: A language and environment for statistical computing. https://www.r-project.org/.

Saenz-Agudelo, P., G. P. Jones, S. R. Thorrold, and S. Planes. 2011. Connectivity dominates larval replenishment in a coastal reef fish metapopulation. Proceedings of the Royal Society B: Biological Sciences 278:2954-61.

Schunter, C., J. Carreras-Carbonell, E. Macpherson, J. Tintoré, E. Vidal-Vijande, A. Pascual, P. Guidetti, and M. Pascual. 2011. Matching genetics with oceanography: directional gene flow in a Mediterranean fish species. Molecular Ecology 20:516781.

Schunter, C., M. Pascual, J. C. Garza, N. Raventos, and E. Macpherson. 2014a. Kinship analyses identify fish dispersal events on a temperate coastline. Proceedings of the Royal Society B: Biological Sciences 281:20140556.

Schunter, C., J. C. Garza, E. Macpherson, and M. Pascual. 2014b. SNP development from RNA-seq data in a non-model fish: how many individuals are needed for accurate allele frequency prediction? Molecular Ecology Resources 14:157-165.

Schunter, C., S. Vollmer, E. Macpherson, and M. Pascual. 2014c. Transcriptome analyses and differential gene expression in a non-model fish species with alternative mating tactics. BMC Genomics 15:167.

630 Selkoe, K. A., S. D. Gaines, J. E. Caselle, and R. R. Warner. 2006. Current shifts and kin 
aggregation explain genetic patchiness in fish recruits. Ecology 87:3082-94.

Selkoe, K., and R. J. Toonen. 2011. Marine connectivity: a new look at pelagic larval duration and genetic metrics of dispersal. Marine Ecology Progress Series 436:291305.

Selwyn, J. D., J. D. Hogan, A. M. Downey-Wall, L. M. Gurski, D. S. Portnoy, and D. D. Heath. 2016. Kin-Aggregations Explain Chaotic Genetic Patchiness, a Commonly

638 Treml, E. A., J. J. Roberts, Y. Chao, P. N. Halpin, H. P. Possingham, and C. Riginos. 2012. Reproductive output and duration of the pelagic larval stage determine

Waples, R. S. 2016. Tiny estimates of the $N_{\mathrm{e}} / N$ ratio in marine fishes: Are they real? seascape-wide connectivity of marine popto
Biology 52:525-537.
Journal of Fish Biology 89:2479-2504.

644 White, C., K. Selkoe, J. Watson, D. A. Siegel, D. C. Zacherl, and R. J. Toonen. 2010. Ocean currents help explain population genetic structure. Proceedings of the Royal Society B: Biological Sciences 277:1685-1694.

Wilson, D. T., and M. I. McCormick. 1999. Microstructure of settlement-marks in the otoliths of tropical reef fishes. Marine Biology 134:29-41.

Wirtz, P. 1978. The behaviour of the Mediterranean Tripterygion species (Pisces, Blennioidei). Zeitschrift fur Tierpsychologie 48:142-174. 


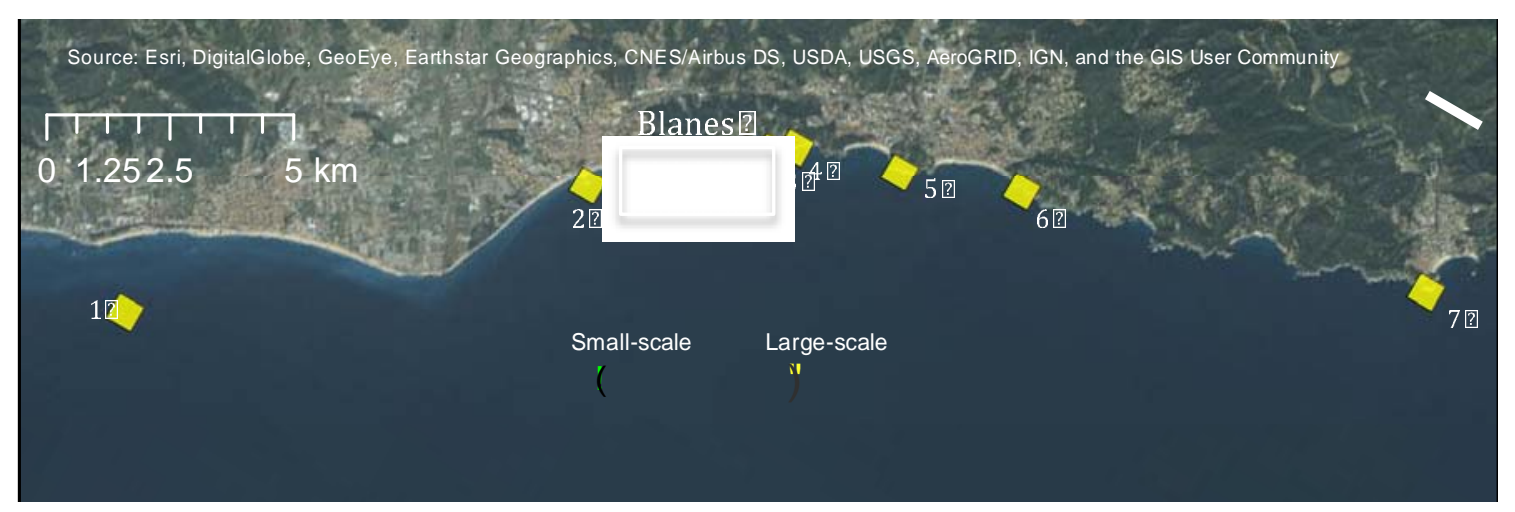

Figure 1: Map of sampling area including the small-scale intensive sampling area (Blanes) and the large-scale collection area. 1) La Pilona, 2) Palomera, 3) Blanes north 4) Clotilde, 5) Lloret de Mar south, 6) Lloret de Mar north, 7) Tossa de Mar.

\section{MIXED-range} dlspersers

2. SHORT-rernge dispersers

\section{MEDIUM-range} dilspersers

\section{HIGH-range dlepersere}
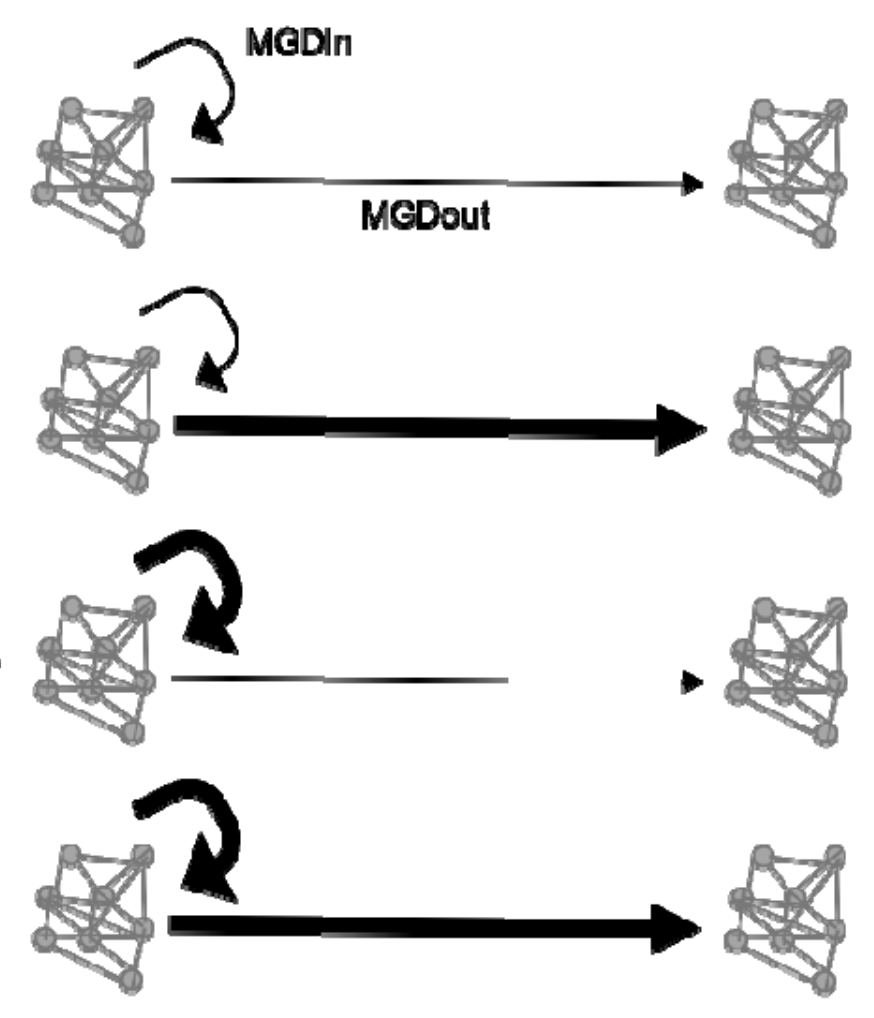

Spat|al Cluster a
Spatal Cluster b

Figure 2: Conceptual Plot showing the four categories of dispersers. Two spatial clusters are represented and the mean genetic distance (MGD) among the individuals within one cluster (MGDin) indicated with a circular arrow and with individuals of other spatial clusters (MGD out) with the straight arrow. The thickness of the lines represents the distance: thick= high MGD, thin=low MGD. 
bioRxiv preprint doi: https://doi.org/10.1101/530451; this version posted January 26,2019 . The copyright holder for this preprint (which was not certified by peer review) is the author/funder, who has granted bioRxiv a license to display the preprint in perpetuity. It is made available under aCC-BY-NC-ND 4.0 International license.

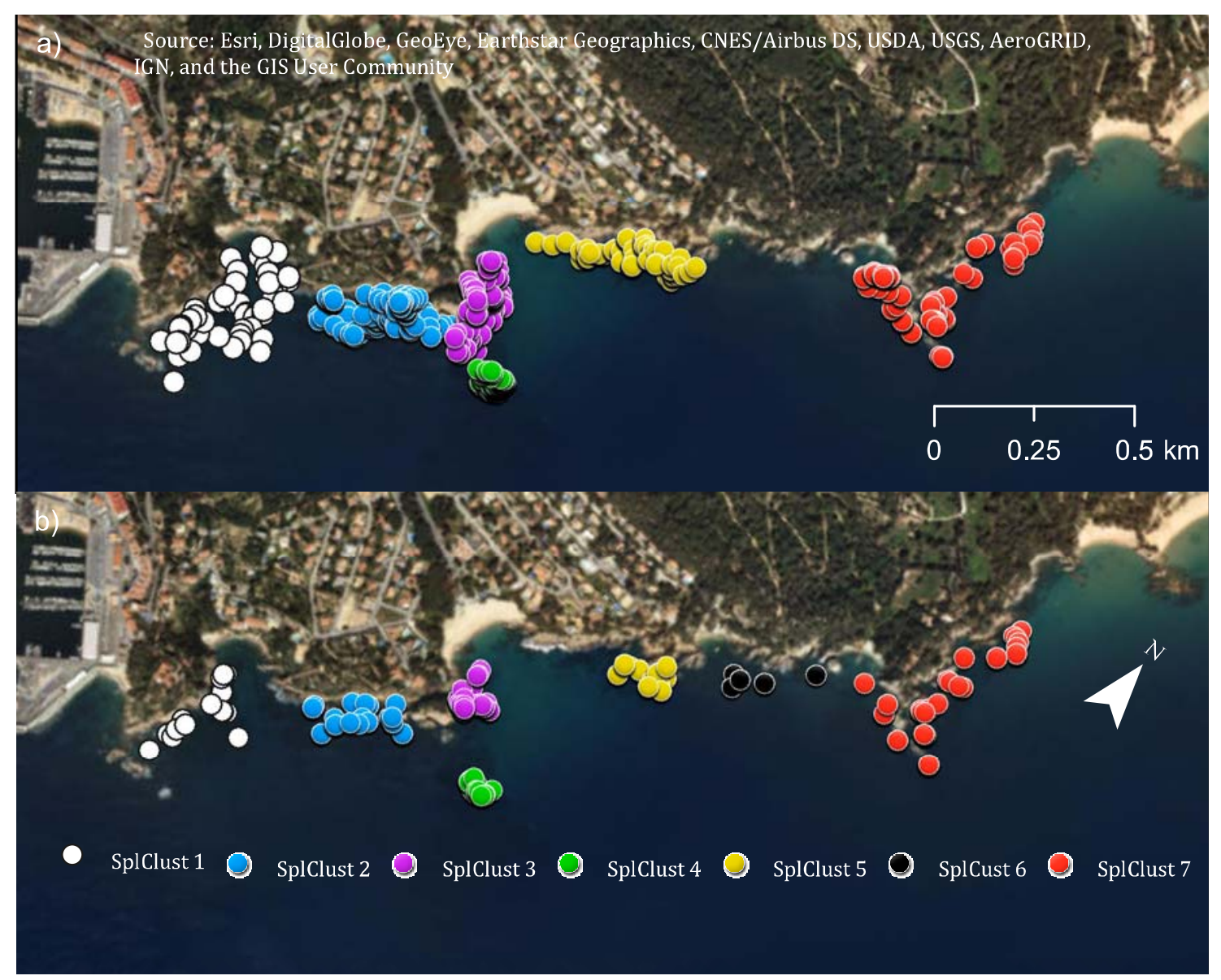

Figure 3: Spatial clusters within the small-scale area for a) adults and b) juveniles. Spatial cluster 6 only exists for the juveniles and few individuals were found. 
bioRxiv preprint doi: https://doi.org/10.1101/530451: this version posted Januarv 26. 2019. The copvright holder for this preprint (which was not certified by peer review) is the author/funder, who has granted bioRxiv a license to display the preprint in perpetuity. It is made available under aCC-BY-NC-ND 4.0 International license.

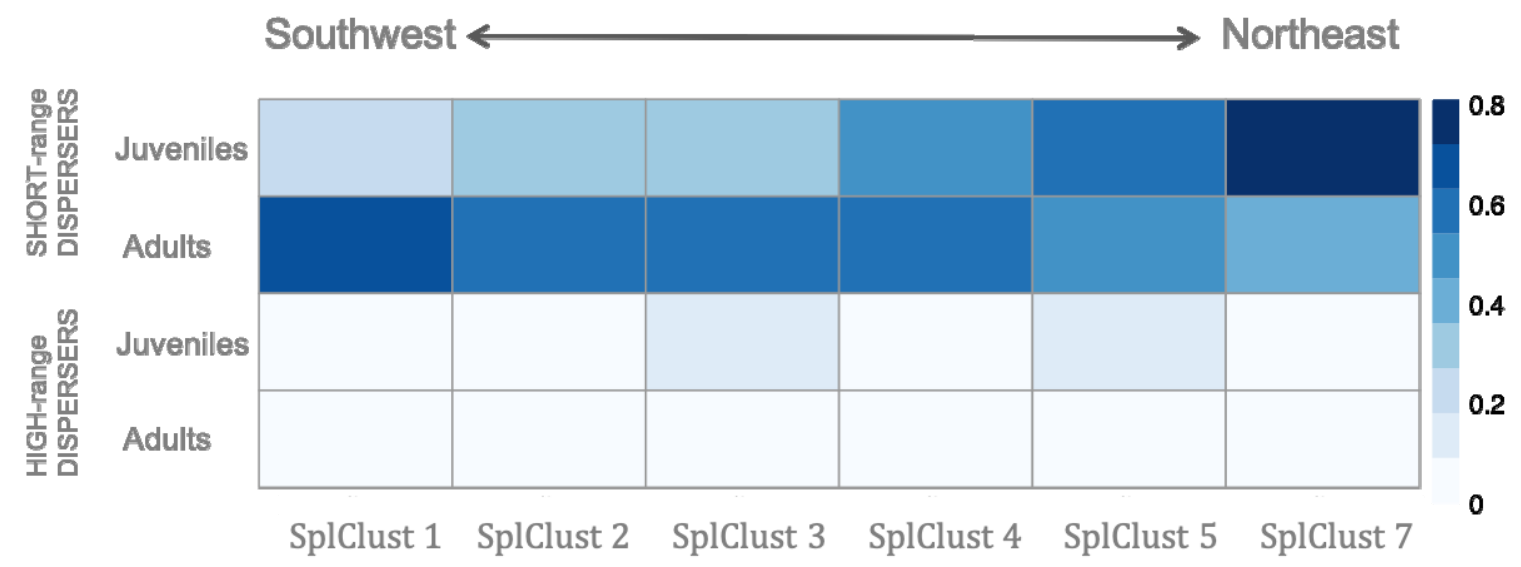

Figure 4: Proportion of adults and juveniles in each spatial cluster (SplClust; Figure 3) in the SHORT-range disperser category, which are individuals with low mean genetic distance (MGD) with respect to their own spatial cluster and a high MGD with respect to other spatial clusters as well as HIGH-range dispersers, which have high MGD to all clusters. SplClust6 is not included because it was only found in juveniles and in very low frequency. 
bioRxiv preprint doi: https://doi.org/10.1101/530451; this version posted January 26,2019 . The copyright holder for this preprint (which was not certified by peer review) is the author/funder, who has granted bioRxiv a license to display the preprint in perpetuity. It is made available under aCC-BY-NC-ND 4.0 International license.

$$
\text { 喜 }
$$

a)

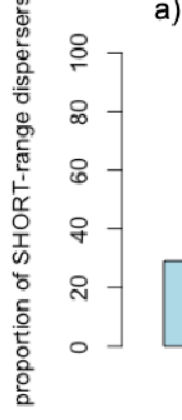

b)

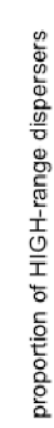
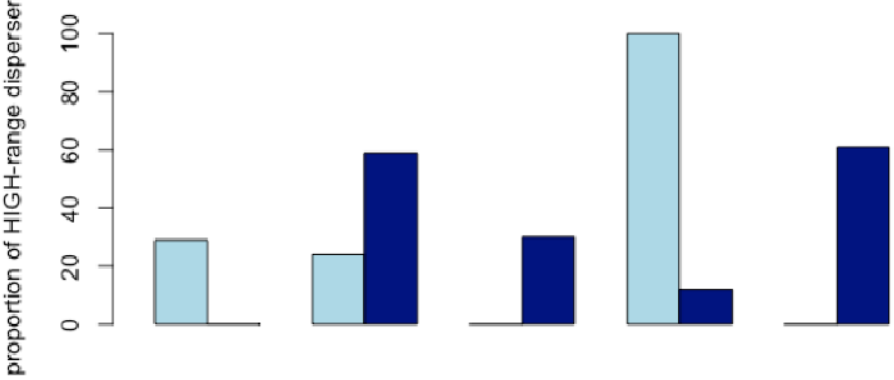

earlyjuveniles

latejuveniles

SplClust1

SplClust2

SplClust3

SplClust4

SpIClust5

SplClust6 SplClust7

SOUTHWEST

$>$ NORTHEAST

Figure 5: Proportion of low dispersers (a) which are individuals with a low mean genetic distance (MGD) with respect to their own spatial cluster and a high MGD with respect to other spatial clusters and high dispersers (b) which are individuals with high MGD with respect to all clusters, in early and late juveniles in each spatial cluster (from Figure 3).

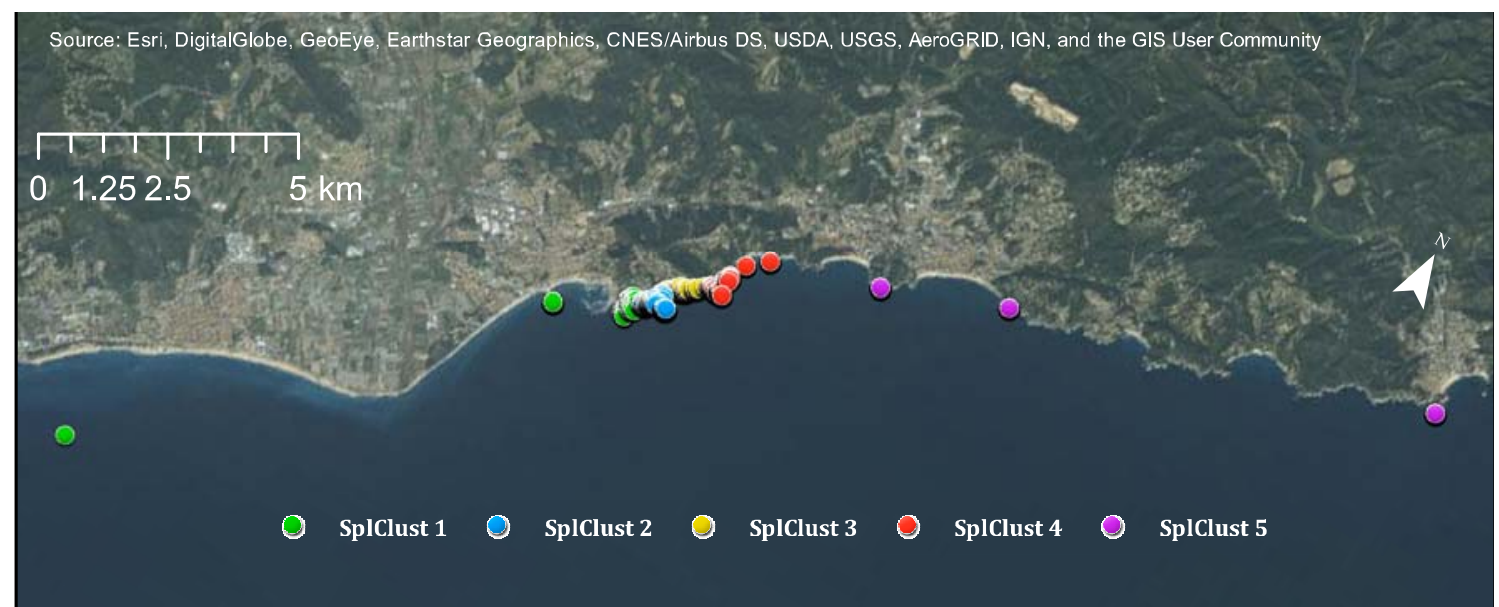

Figure 6: Spatial clusters for juveniles within the whole large-scale area 